\title{
Research Paper: Effectiveness of Psychological Empowerment on General Health of Mothers of Children With Disability Under the Community-Based Rehabilitation Program
}

\author{
Fateme Fallahi ${ }^{1} \odot{ }^{*}$ Ghorban Hemati Alamdarloo $^{1} \odot$ \\ 1. Department of Special Education, School of Education \& Psychology, Shiraz University, Shiraz, Iran
}

\begin{tabular}{|l|l|}
\hline $\begin{array}{c}\text { Use your device to scan } \\
\text { and read the article online }\end{array}$ & $\begin{array}{l}\text { Cfteation Fallahi F, Hemati Alamdarloo Gh. [Effectiveness of Psychological Empowerment on General Health of Mothers } \\
\text { of Children With Disability Under the Community-Based Rehabilitation Program (Persian)]. Archives of Rehabilitation. 2019; } \\
\text { 19(4):326-339. http://dx.doi.org/10.32598/rj.19.4.326 }\end{array}$ \\
d. http://dx.doi.org/10.32598/rj.19.4.326
\end{tabular}

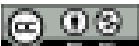

Received: 16 Apr 2018 Accepted: 25 Oct 2018 Available Online: 01 Jan 2019

\section{ABSTRACT}

Objective Parents face a lot of challenges with the birth of a child with disability. According to research findings, mothers of the children with disabilities have lower levels of mental health than mothers of typically-developing children, and the presence of disabilities in family members creates mental and emotional problems for other family members, especially mothers. These mothers are unaware of their physical and mental health as compared to mothers of typically-developing children. These conditions can lead to mothers' losing interest in establishing relationships with their relatives that can end in depression and worsening of mothers' mental health. Therefore, it is necessary to pay attention to the psychological status of mothers of children with disabilities and consider the essential role of parents in planning any intervention program for people with disabilities. For this reason, the purpose of this study was to investigate the effectiveness of psychological empowerment on the general health of mothers of the children with disabilities in a community-based rehabilitation program.

Materials \& Methods The research method was quasi-experimental and with pre-test and post-test design and control group. The statistical population of this study included all mothers with children with disabilities in the Marvdasht City, Iran, who participated in the community-based rehabilitation program in 2017. Out of this community, 30 individuals were selected by convenience sampling method and randomly divided into two groups of 15 each (control and experimental). Both groups were taken pretest and the experimental group received psychological empowerment intervention in ten 90-minute sessions (two sessions per week), while this intervention was not provided to the control group and at the end, a post-test was performed for both groups. The general health questionnaire was 28 questions from Goldberg and Hillier. The obtained data were analyzed by analysis of covariance.

Results The intervention of the psychological empowerment program on general health made a significant difference between the two experimental and control groups in the post-test results $(P<0.001)$. In other words, general health in the experimental group was significantly better than that in the control group. Therefore, psychological empowerment affects the general health of mothers of the children with disabilities covered by community-based rehabilitation programs. In addition, the intervention of the psychological empowerment program on the subscales of physical health caused a significant difference between the experimental and control groups in the post-test $(P<0.001)$, i.e. physical health in the experimental group was significantly better than that in the control group. Moreover, the intervention on the anxiety subscale caused a significant difference between the experimental and control groups in the post-test $(\mathrm{P}<0.001)$. It means that anxiety in the experimental group was significantly reduced compared to the control group. Finally, the intervention of the psychological empowerment program on the subscale of the disorder in social function caused a significant difference between the experimental and control post-test results $(\mathrm{P}<0.001)$. In other words, the disorder in social function in the experimental

\section{* Corresponding Author:}

Ghorban Hemati Alamdarloo, PhD.

Address: Department of Special Education, School of Education \& Psychology, Shiraz University, Shiraz, Iran.

Tel: +98 (71) 36134654

E-Mail: ghemati@shirazu.ac.ir 
Keywords:

Psychological empowerment, General health, Communitybased rehabilitation group significantly was lower compared to the control group. It is worth noting that according to the research findings, the intervention of the psychological empowerment program did not have a significant effect on the subscales of depression. Therefore, psychological empowerment affected three subscales of general health (i.e. physical health, anxiety and social function disorder) of mothers of children with disability under community-based rehabilitation program.

Conclusion Present study indicates that psychological empowerment improves the general health of mothers covered by community-based rehabilitation program and has affected three subscales of general health (physical health, anxiety, and social function disorder) of mothers of children with disability under community-based rehabilitation program. Therefore, officials and custodians of the communitybased rehabilitation program must consider psychological empowerment important for its wide-ranging implementation and its important implications for domestic action. It should be reminded that the present study was conducted only on mothers covered by the community-based rehabilitation program, so its results should be generalized to other mothers with caution. The lack of follow-up was also one of the limitations of the present study. Therefore, for future research, it is suggested that a program be run with the presence of both parents. A follow-up study should also be conducted to investigate the continuation of the effects of intervention. It is also recommended that the authorities of the welfare organization provide psychological empowerment workshops for all members of the family with disabilities by allocating more funds and supporting community-based associations with rehabilitation programs. In the end, it is suggested that a psychological empowerment program be designed and implemented to improve the general health of mothers of children with disabilities covered by community-based rehabilitation program. 
This Page Intentionally Left Blank 


\title{
اثربخشى توانمندسازى روانشناختى بر سلامت عمومى مادران داراى فرزند ناتوان تحت يوشش برنامه توانبخشى مبتنى بر جامعه
}

\author{
فاطمه فلاحى' ه. • قربان همتى علمدارلو' \\ 1- كروه آموزش كودكان استثنايى، دانشكده علوم تربيتى وروانشأسى، دانشكاه شيراز، شيرازء ايران.
}

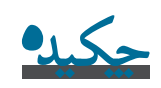

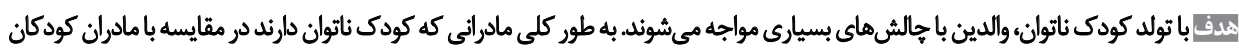

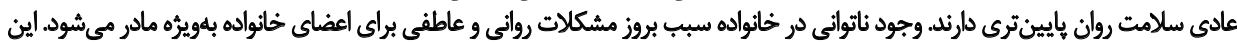

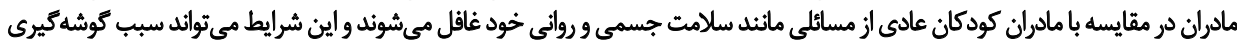

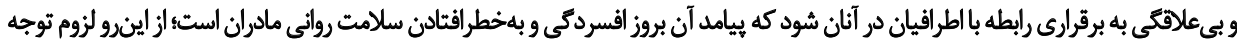

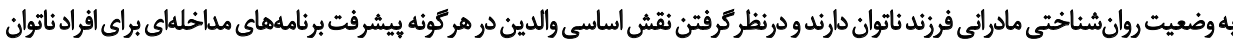

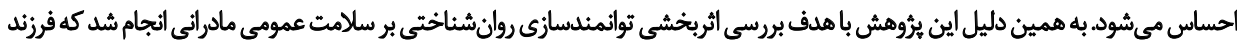

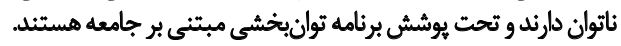

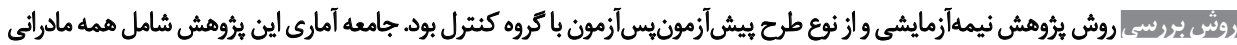

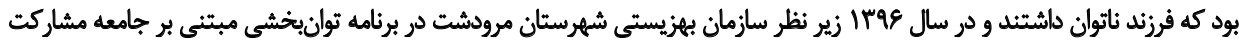

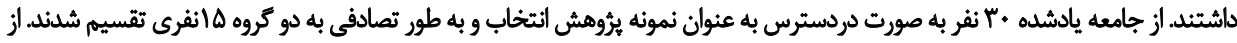

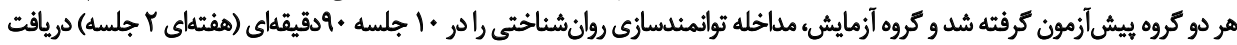

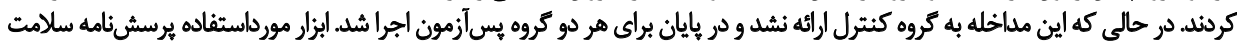

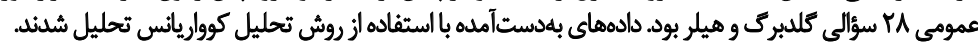

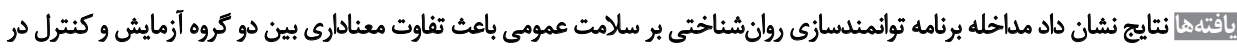

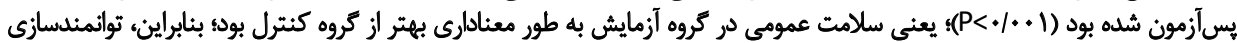

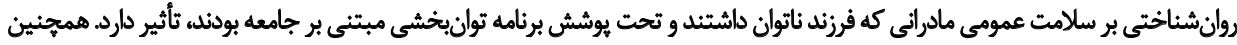

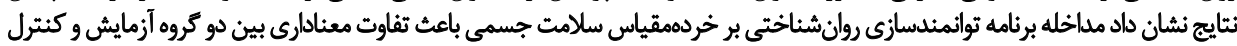

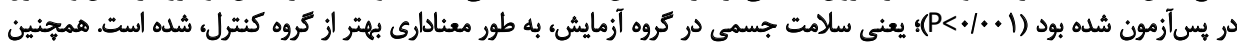

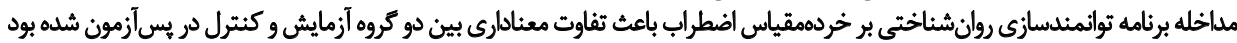

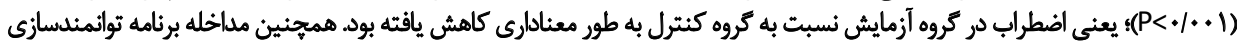

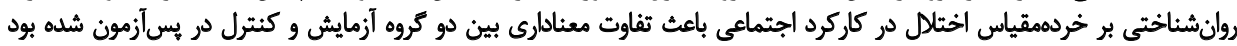

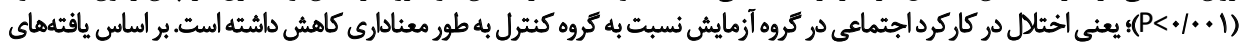

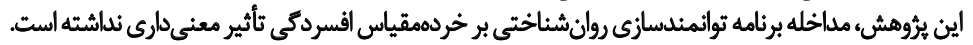

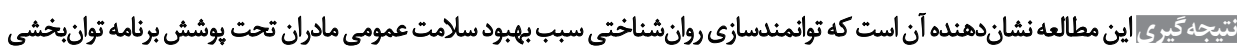

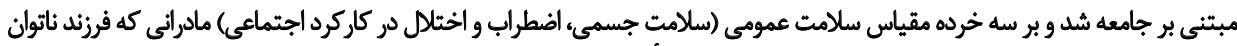

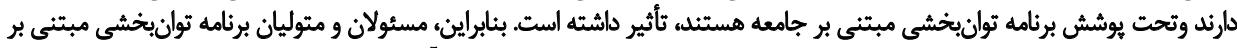

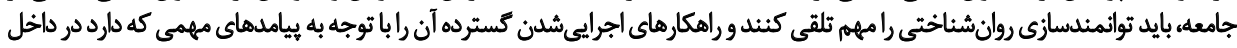

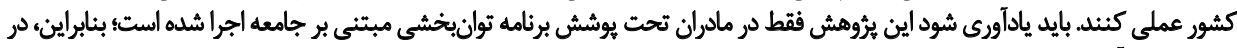

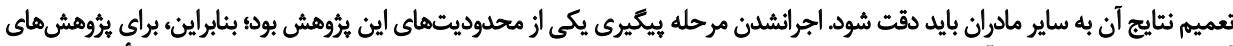

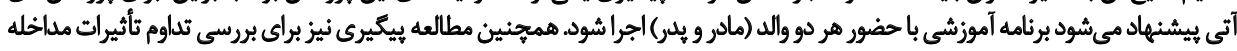

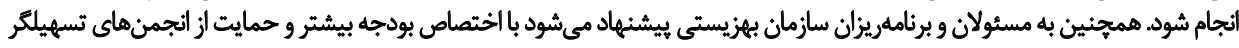

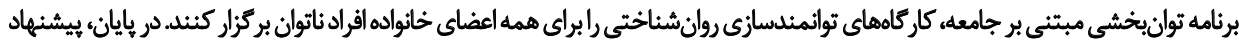

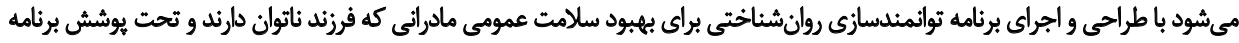

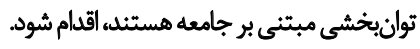

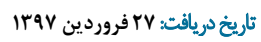

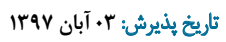

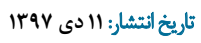


است آموزش والدين بهترين راه حمايت از افراد ناتوان و خانواده

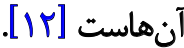

توانمندسازى آخرين مؤلفه ماتريس توانبخشى مبتنى بر جامعانه

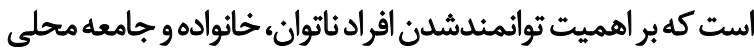

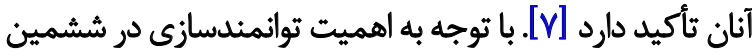

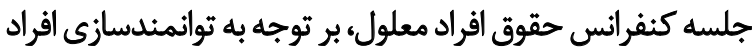

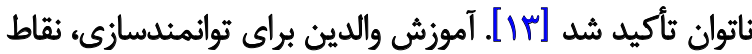

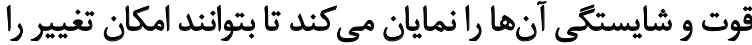

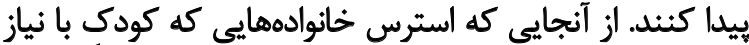

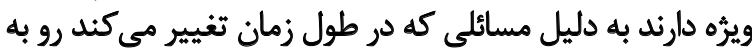

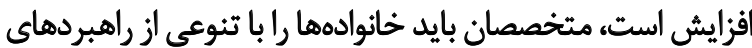

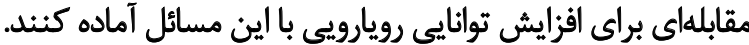

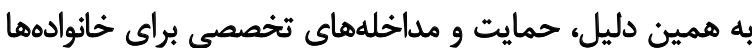

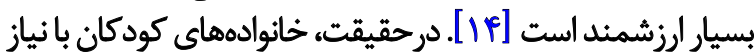

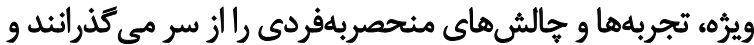

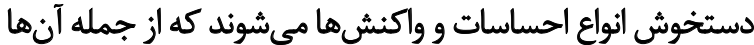

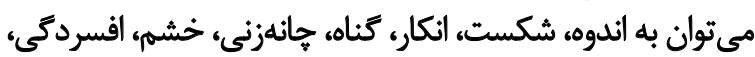
يذيرش و استرس اشاره كرد [F]

در تأييد اين موضوع، يافتههاي يُروهشى نشان مي دهند مادئ مادران

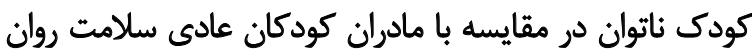

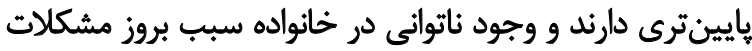

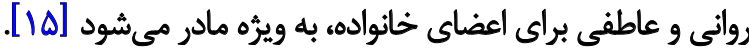

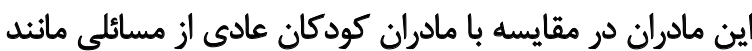

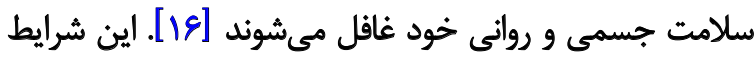

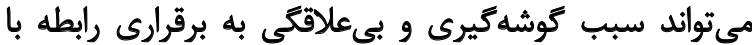

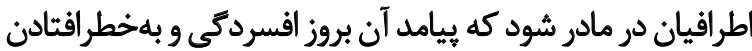

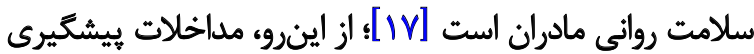

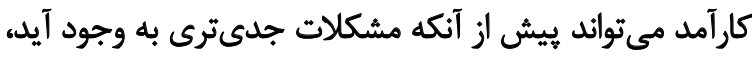

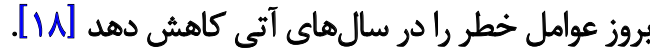
در همين راستا، بديعيور، سليمى و كلانتركوشه در يروهشى تعارئ

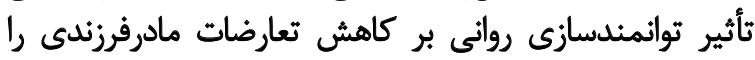

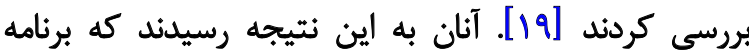

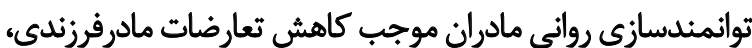

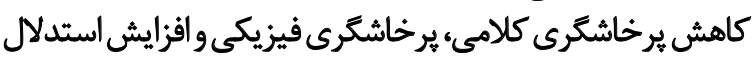

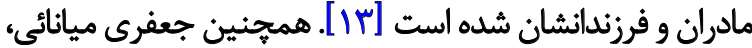

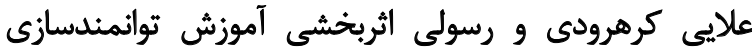

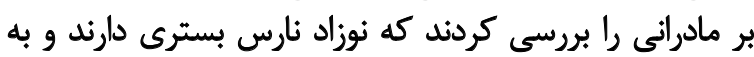

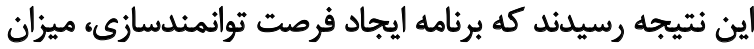

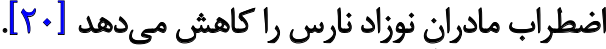

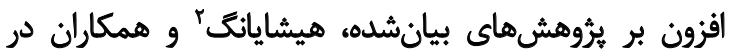

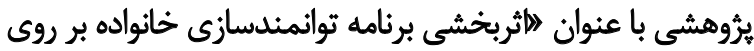

مقدمه

با ورود كودى جديد به خانواده، ساختار و ويويايى خانواده

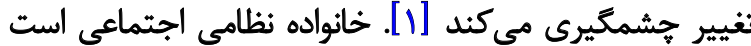

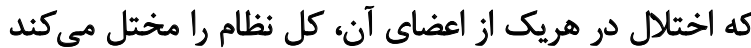

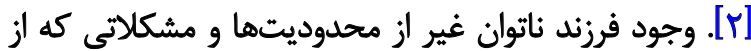

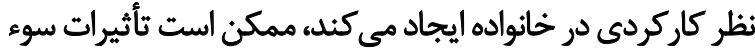

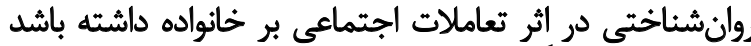

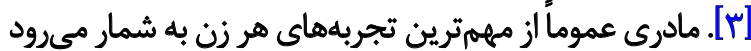

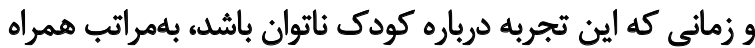

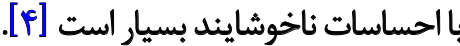

اولين شخصى كه به طور مستقيم با كودى ارتباط برقرار

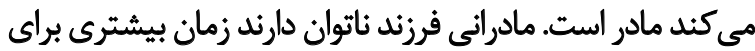

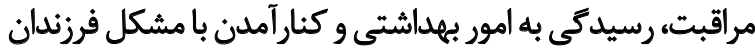

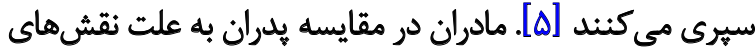

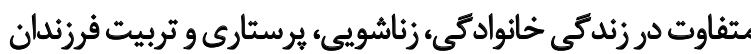

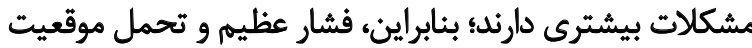

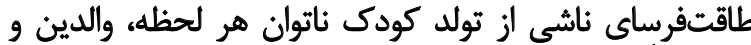

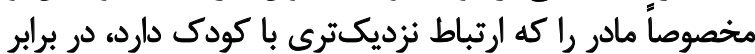

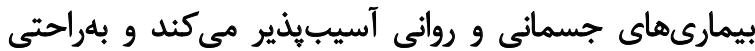

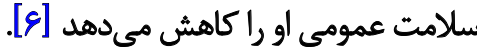

در دو دهه اخير، برنامههاى توانبخشى مبتنى بر براني جامعه' براى

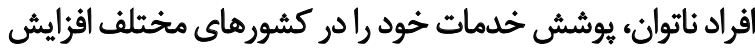

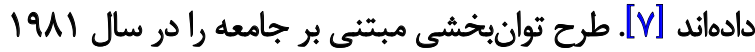

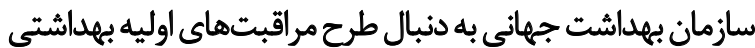

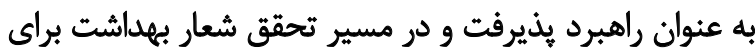

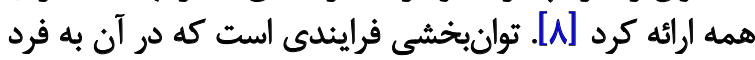

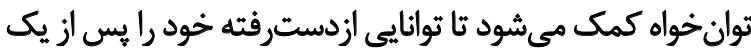

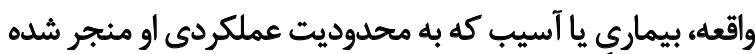

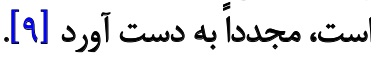

توانبخشى مبتنى بر جامعه روى افزرايش كيفيت زندكى افراد ناتوان و خانوادههايشان، رفع نيازهاني اساسى آنهان آنها، حصول

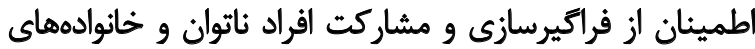

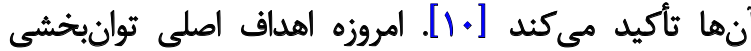

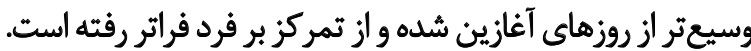

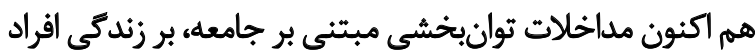

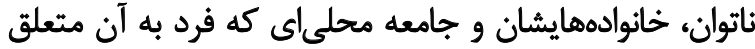

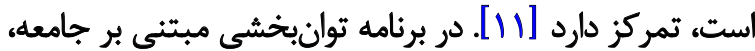

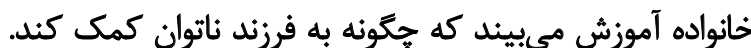

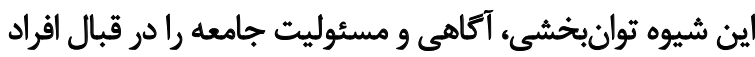

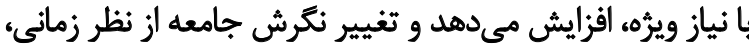

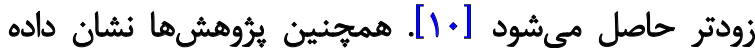

1. Community-Based Rehabilitation 
بود كه فرزند ناتوان داشتند و زير نظر سازمان بهزيستى شهرستان

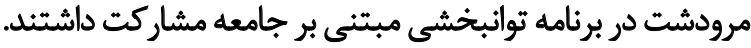

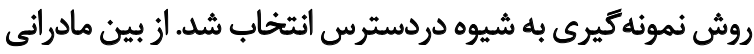

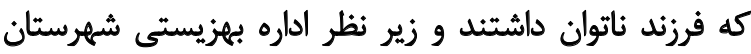

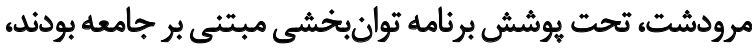

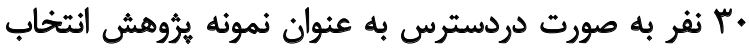

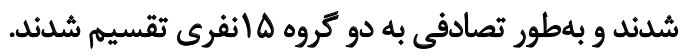
به منظور كردآورى دادهاى ثئوهش از ابزارهاى زير بهره

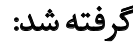
يرسش نامه سامث عمومى در اين برُوهش براى ارزيابي سلامت عمومى مشاركت كنئدكان

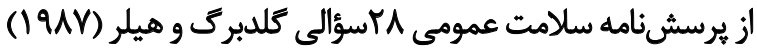

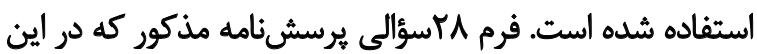

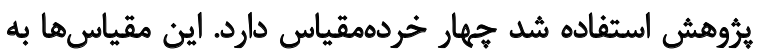

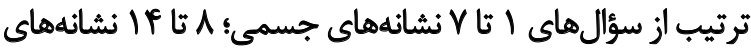

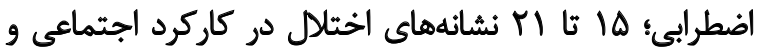

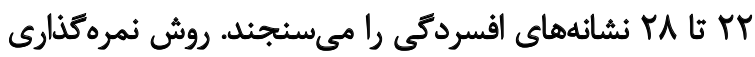

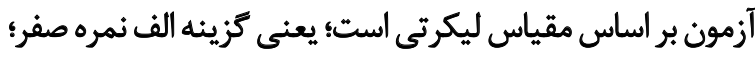

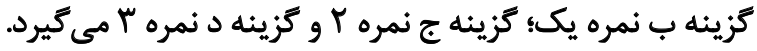

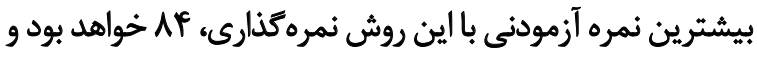

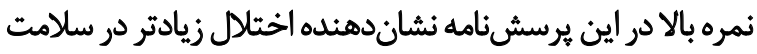

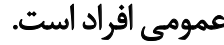

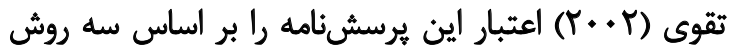

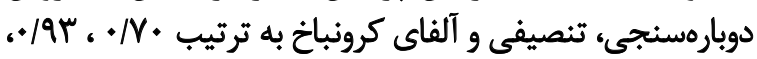

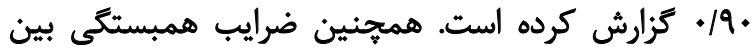

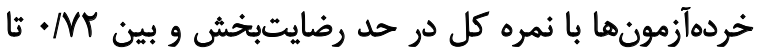

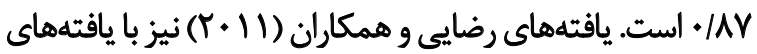

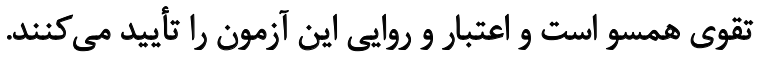

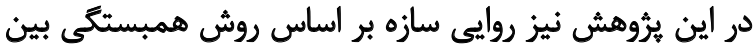

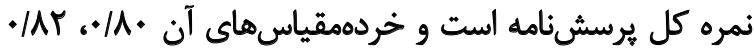

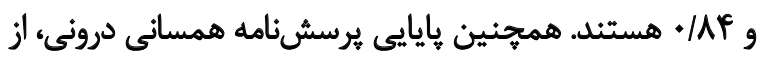

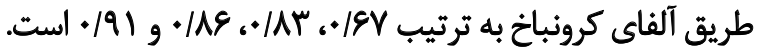

\section{برثامه مداخله توانمثندسازى روانشئاخثى}

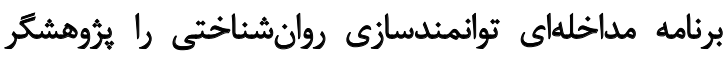

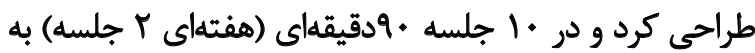

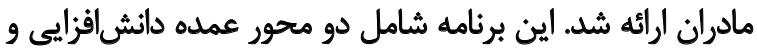

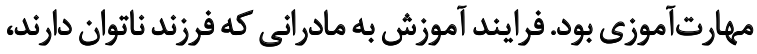

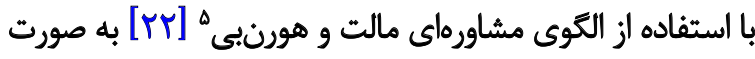
كروهى طراحى شد. بدين صورت كه ابتدا موضوع يا مسئله مطرح

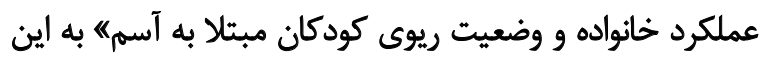

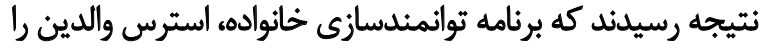

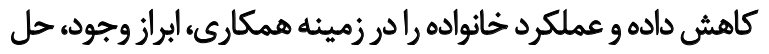

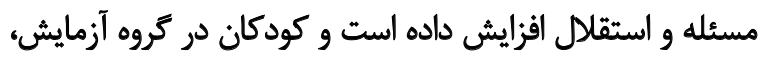

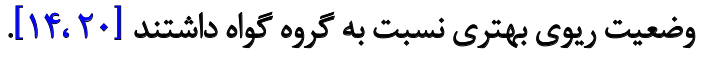

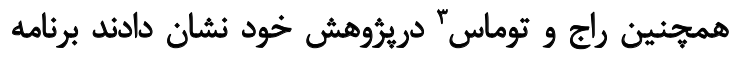

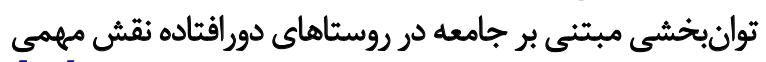

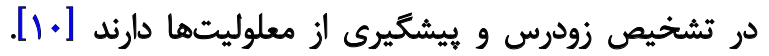

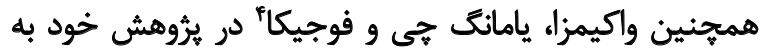

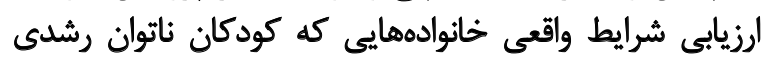

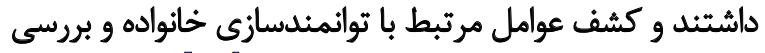

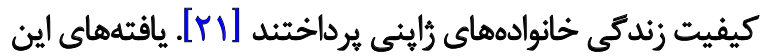

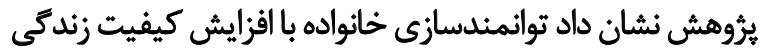

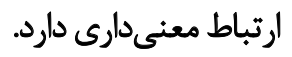

با توجه به اينكه نقش توانبخشى مبتنى بر جامعه حفظ حقوق

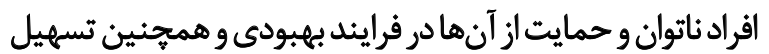

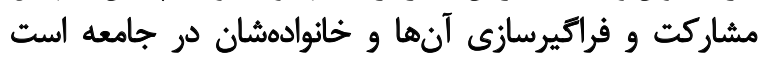

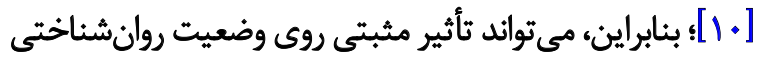

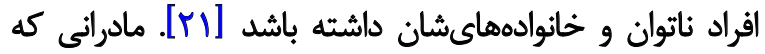

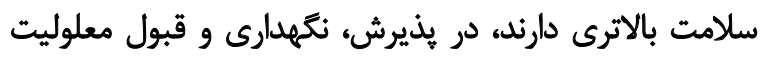

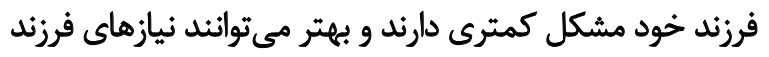

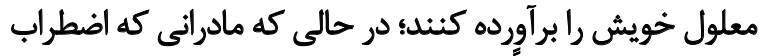

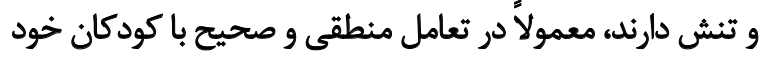

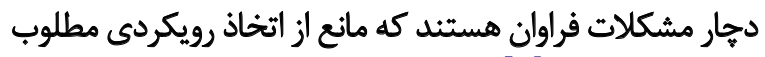

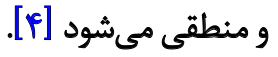

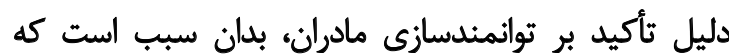

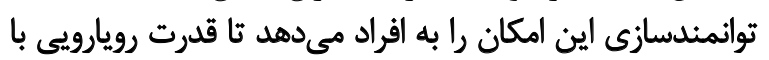

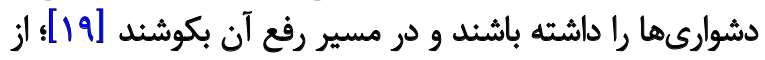

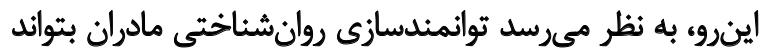

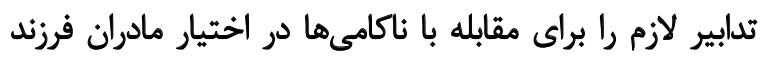

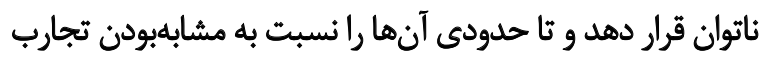

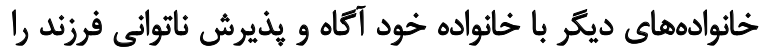

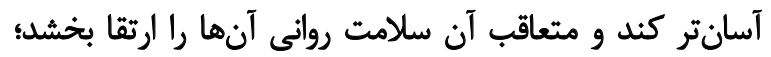

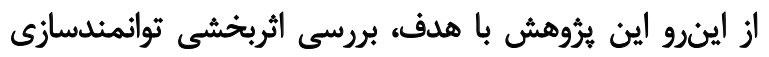

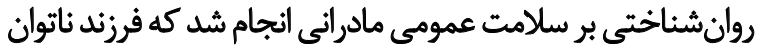

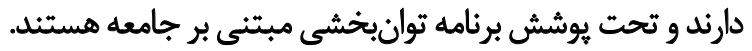

$$
\text { ووش بروسى }
$$

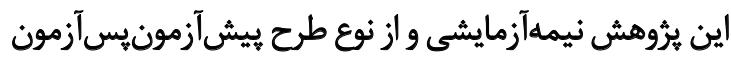

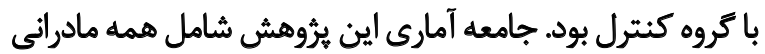


جدول ا. خلاصه زمانبندى و محتواي جلسات توائمندسازى روانشناختى

\begin{tabular}{|c|c|}
\hline اهداف & جلسات \\
\hline 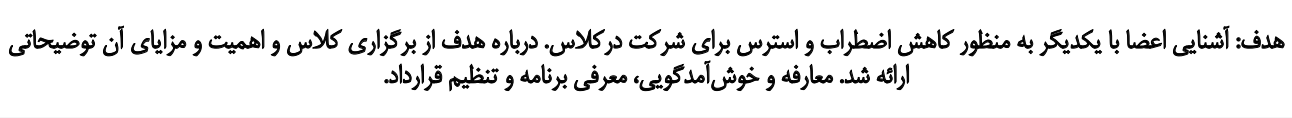 & جلمعارفه (اول \\
\hline 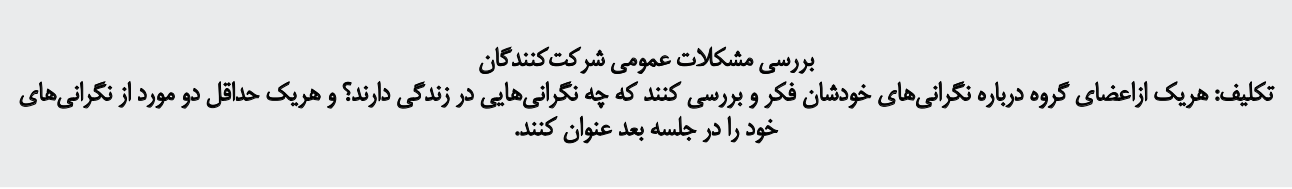 & بورسى جالشهاه دوم \\
\hline بررسى تكليف جلسه قبل و بحث با اعضا درباره جالش هاى اقراد ناتوان & 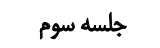 \\
\hline 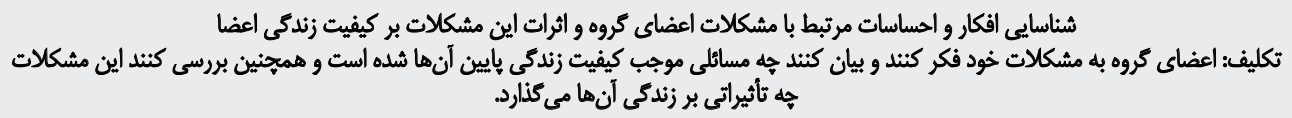 & 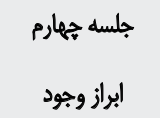 \\
\hline 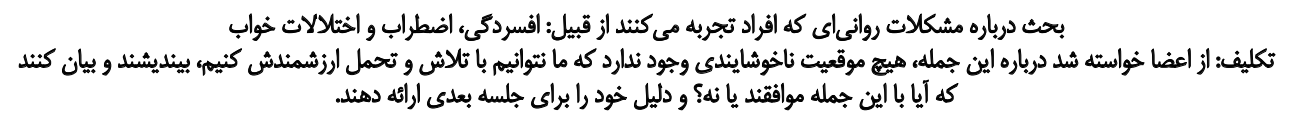 & 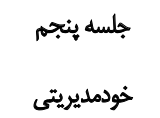 \\
\hline 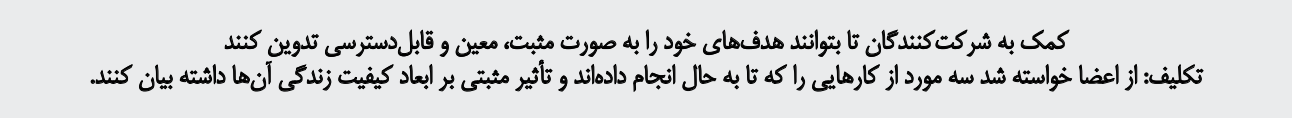 & هلسه شيشمى \\
\hline 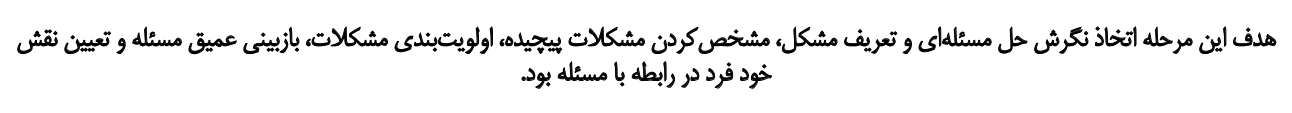 & مجلسه هفتم \\
\hline 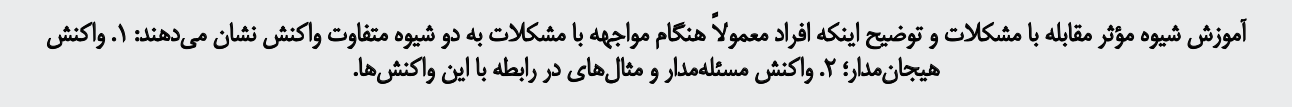 & كتلسه هشتم \\
\hline آموزش مثبتانديشى و بررسى الثر مثبث آن بر زندكى & مثلسه نمهم \\
\hline 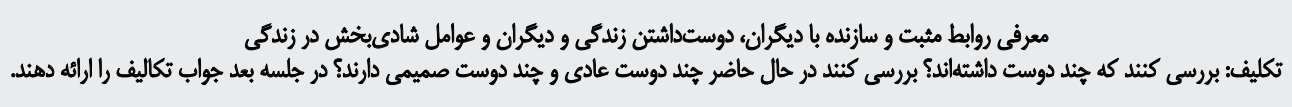 & مجلسه دهم \\
\hline
\end{tabular}

توانبخننى

ديكر به صورت كتبى در اختيار مادران قرار مى كرفت. در جدول شماره ا خلاصه برنامه آموزشى ارائه شده است

$$
\text { شيوها مرا }
$$

براى اجراي اين يُوهش نخست كروه نمونه از بين مادرانى كه

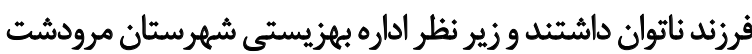

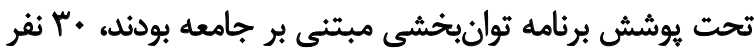

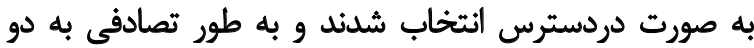

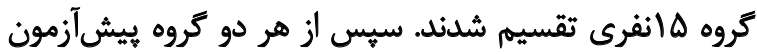

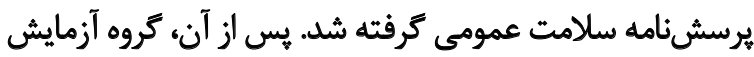

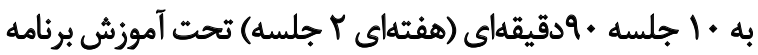

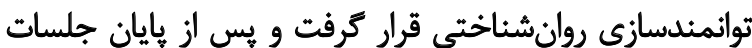

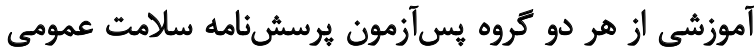
كرفته شد. تروه كنترل در طول زمانى كي تروه بره آزمايش برنامه

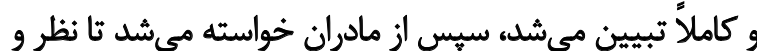

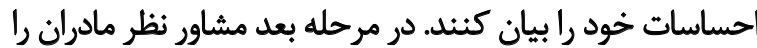

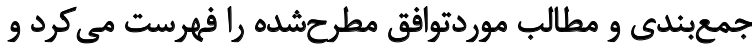

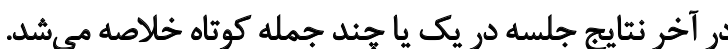
همجنين در زمينه دانشافزايي، اطلاعاتى درباره معلوليتهاء

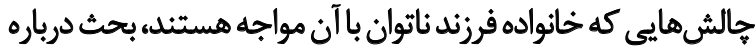

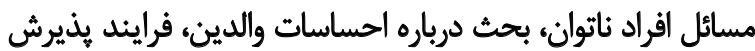

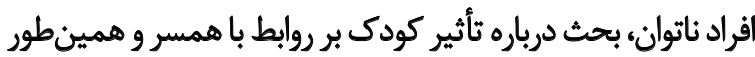

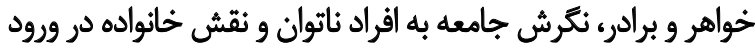

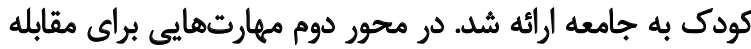

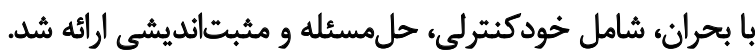

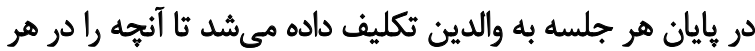

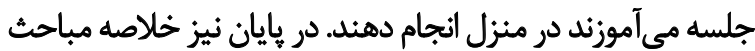

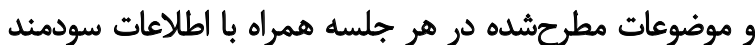


جدول Y. شاخص توصيفى مقياس سلامت عمومى

\begin{tabular}{|c|c|c|c|c|c|c|c|c|c|c|c|}
\hline \multicolumn{5}{|c|}{ يسآزمون } & \multicolumn{5}{|c|}{ ييشأزمون } & \multirow[b]{2}{*}{ كروه } & \multirow[b]{2}{*}{ شاخهص } \\
\hline $\mathbf{P}$ & z & أنحاثراف & مياتكين & فراوانى & $\mathbf{P}$ & $\mathbf{z}$ & استاندارد اف & مياتكين & فراوانى & & \\
\hline.$/ 9 \Delta$. & . /QT. & q/eV & $r V / .$. & 10 & $\cdot / A n$ & . & $9 / / F$ & $r .1 .$. & 10 & كثترل & سلامت \\
\hline$\cdot / A+r$ & . & $\Delta / A$ & M/qu & 10 & $\cdot M$ & |FAr & $1 . N \Delta$ & $\pi / q \pi$ & 10 & آزمايش & عهومى \\
\hline
\end{tabular}

توانبخننى

جدول ب. نتايج آزمون تى مستقل براى متغير سلامت عمومى

\begin{tabular}{|c|c|c|c|c|c|c|c|}
\hline سطح معنى دارى & درجه آزادى & $\mathbf{T}$ & انحراف معيار & مياتكين & تعداد & كروه & متغير \\
\hline \multirow[b]{2}{*}{ 1... } & \multirow[b]{2}{*}{ TA } & \multirow[b]{2}{*}{$P / M M$} & 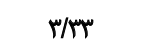 & r/.... & 10 & كتترل & \multirow[b]{2}{*}{ سلامت عهومى } \\
\hline & & & $V / \Delta \Delta$ & $\mid r / \ldots \ldots$ & 10 & آزماش & \\
\hline
\end{tabular}

توانبخننى

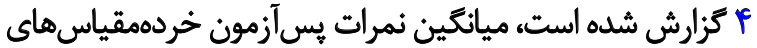

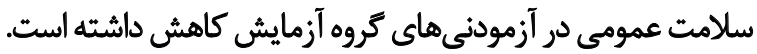
براى بررسى اينكه تثاوت بين دو زروه در يسآزمون

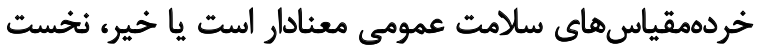

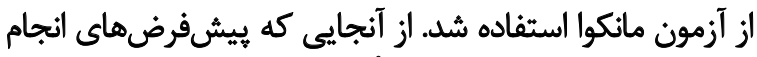

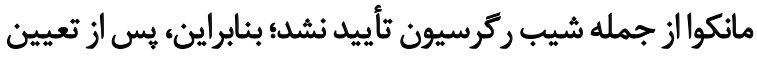

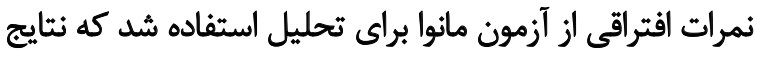

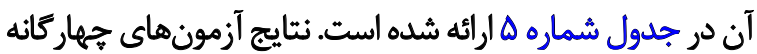

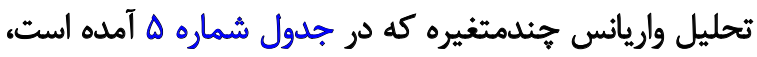

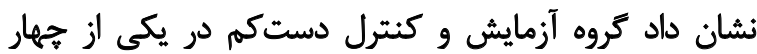

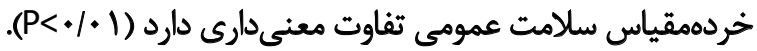

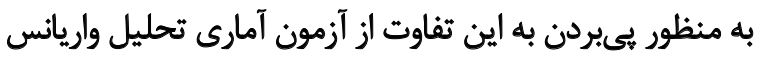

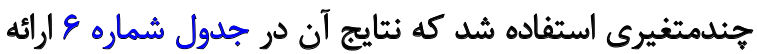
شله است.

نتيايج اين جلدول نشان هي دهد هداخله برنامه تواثمندسازى روانشئاختى بر خردهمقياس سلامت جسمى باعث تفاوت معنادارى

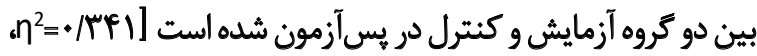

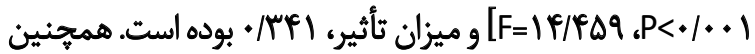
مداخله برنامه توانمندسازى روانشناختى بر خردهمقياس اضطراب تاني

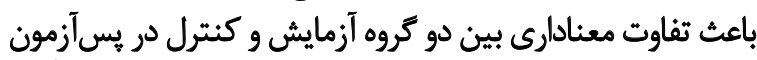

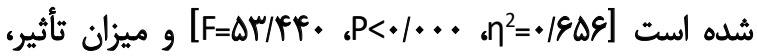

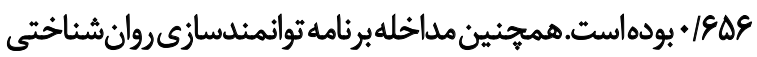

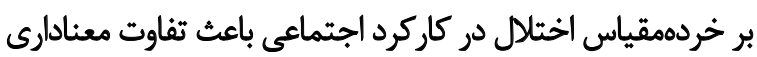

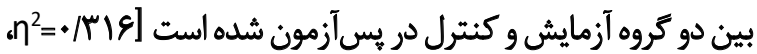

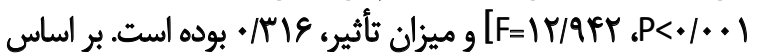

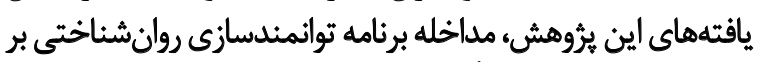

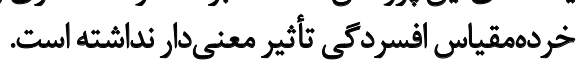

توانمندسازى روانشيناختي رادريافت كردند، هيجكونه مداخلهاي

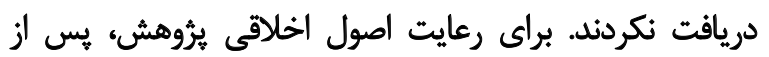

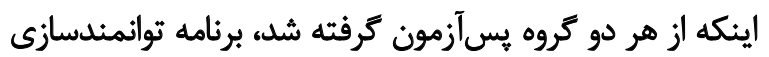

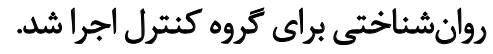

Wdiel

در اين بخش نتست دادههاى آمار توصيفى از قبيل فراوانى،

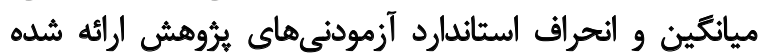

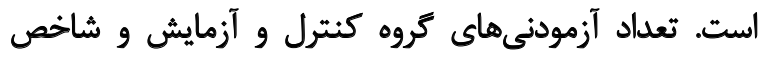

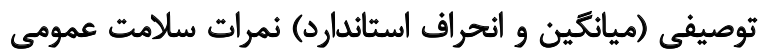

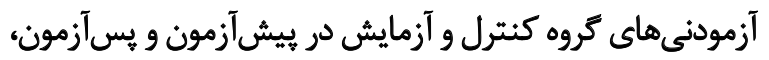

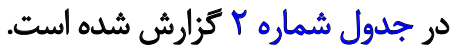
همانطور كه در جدول شماره Y Sزارش شده است، كاهش

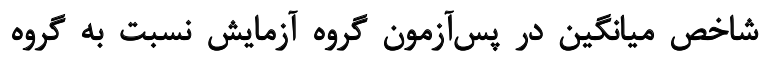

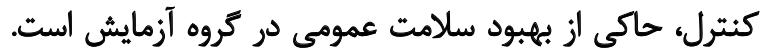

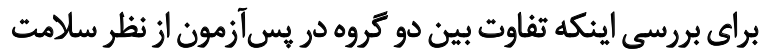

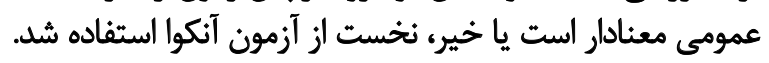

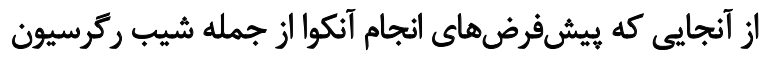

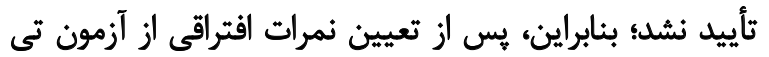

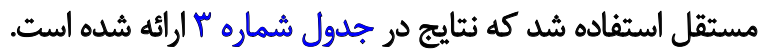

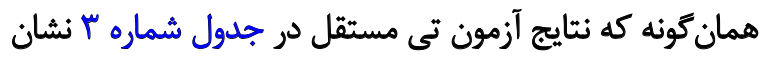

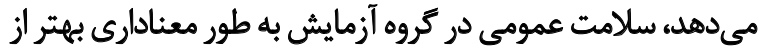

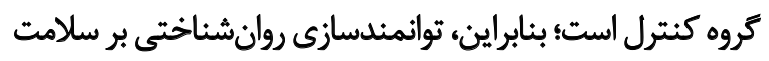

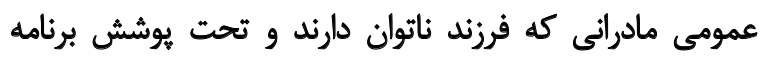
توانبخشى مبتنى بر جامعه هستند، ثأثير دارد. همجنين در جلول شيماره f شاخص هاي توصيفي نمرات

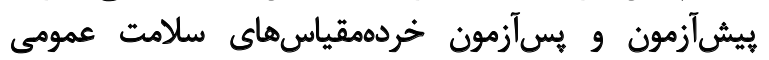
آزمودنىها كزارش شده است. همانطون هون كه در جدول شماره 
جدول †. شاخصهاي توصيفي نمرات خردهمقياسهاي سلامت عمومي آزمودنىهاي كروه كثترل و آزمايش

\begin{tabular}{|c|c|c|c|c|c|c|c|c|c|}
\hline \multicolumn{4}{|c|}{ يسأزمون } & \multicolumn{4}{|c|}{ ييشآزمون } & \multirow{2}{*}{ كروه } & \multirow{2}{*}{ خردهمقياس } \\
\hline $\mathbf{P}$ & z & انحراف معيار & ميائكين & $P$ & z & انحراف معيار & ميائكين & & \\
\hline - NAF &.$/ \varepsilon \Delta \Delta$ & $r / M$ & V/TE & - Mar & - lapt & $r / 1 \Delta$ & Nar & كثترل & \\
\hline . Isif & - NAA & r/IV & $f / \Lambda$. & . 1904 & $\cdot / N \cdot 1$ & ו & $N N$ & أزمايش & سلامت جسمائى \\
\hline.$/ 910$ & - NaY & r/fe & NeE &.$/ 914$ &.$/ \Delta \Delta A$ & $r / v \Lambda$ & NaT & كنترل & \\
\hline.$/ 91 Y$ & .1051 & r/fOA & $\Delta / 8$. & $\cdot / A n$ & . 1094 & $\pi / \pi$ & $\mid r / .9$ & أزمايش & |فضطرابب \\
\hline . & $18+1$ & $F(8)$ & $F / N$ & .19 .9 &.$/ \Delta C H$ & $r / 99$ & g/Te & كنترل & \\
\hline +/AIF & $+/ 119$ & I/ar & $T / T E$ & .1988 &.$/ 49 \gamma$ & $\Delta / \Delta T$ & g/K & أزمايش & افسردكى \\
\hline.$/ K 19$ & $1 / . \Delta 1$ & $1 / \pi \Delta$ & $g / 4$. & שצח/. &.$/ 979$ & $T / T A$ & g/Re & كنترل & th \\
\hline . MIV &.$/ 897$ & $T / T \Delta$ & QTe & - IMP & - $/ \Delta A \mid$ & $\Delta / \Delta r$ & $E / N^{\prime}$ & أزمايش & \\
\hline
\end{tabular}

توانبخننى

جدول ه. نتايج تحليل واريائس جندمتغيره براي خر هممقياس هاى سلامت عمومى

\begin{tabular}{|c|c|c|c|c|c|}
\hline ضريب اتا & سطح معني إرى & مرجبه آزازئ & $F$ & ارزئ & اثي \\
\hline - peqp & .1000 & $H / \ldots$ & $\Delta / 119$ & - /eqp & اثر ييالايى \\
\hline$+/ f a f$ & $+1+0 \Delta$ & $H / \ldots+\ldots$ & $\Delta / 119$ & $+10+8$ & لامبداي ويلكس \\
\hline . Fqp & $+10+\Delta$ & $4 / 0+\ldots$ & $\Delta / 119$ & */9Yo & اتر هاتليئك \\
\hline . $/$ fqr & $1+00$ & $H / \ldots$ & $0 / 119$ & +/9Yo & بزركترين ريشهروى \\
\hline
\end{tabular}

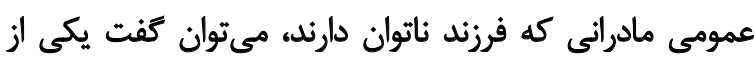

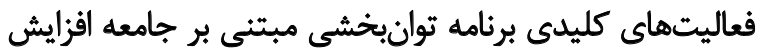

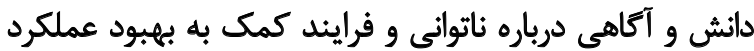

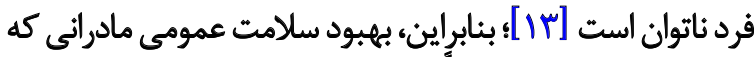

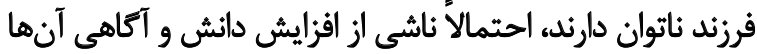

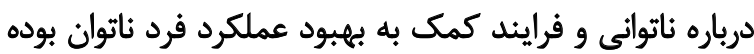

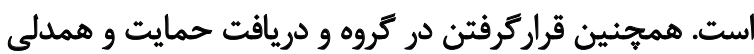

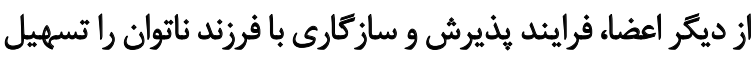

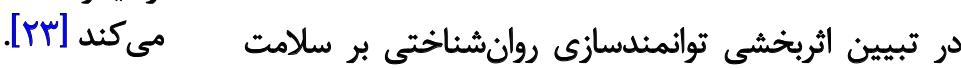

جدول 9.نتايج تحليل واريانس جندمتغيره براى خردهمقياس هاى سلامت عمومى

\begin{tabular}{|c|c|c|c|c|c|c|c|}
\hline ضريب اتا & سطح معنادارى & Fسبت F & ميانكين مجذورات & درجه آزادى & مجموع مجذورات & منيع تغييرات & منبع تغييرات \\
\hline.$/ M 1$ & $1 . .1$ & $\mid F / x \Delta q$ & QNA.. & 1 & $\Delta N A .$. & سلامت جسمانى & \\
\hline.$/ 9 \Delta 9$ & $\%$ & $\Delta r / 4 \varphi$. & $r v \%$ & 1 & $r \gamma+\ldots$ & اضطراب & \\
\hline$. / 1 / r$ & $\% n$ & $r / \Delta / Y$ & $\Delta \cdot N \cdot \cdot$ & 1 & $\Delta \cdot N \cdot \cdot$ & افسردمىى & كروه \\
\hline S & $.1 . .1$ & IT/ATY & $r \% / \%$. & 1 & $r \% / r .$. & اختلال در كاركرد & \\
\hline
\end{tabular}


نشائهاي افسردمى تأثير معنى دار نداشته است. در تبيين اين

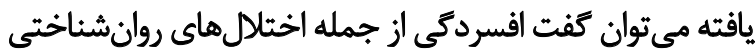
شديد است كه بهيبود آن نياز به مداخله تمانه تركيبى (دارودرمانى،

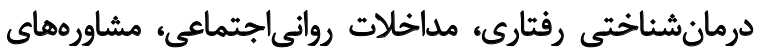

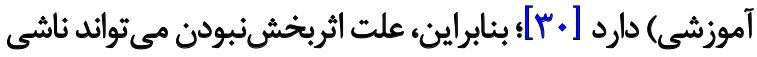

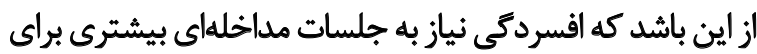

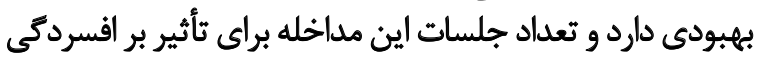
كم بوده است. تثيجلميرى

نقش توانبخشى مبتنى بر جامعه، كمك به فرايند توانمندسازي

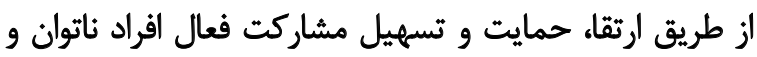

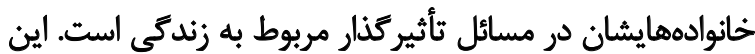

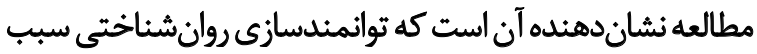

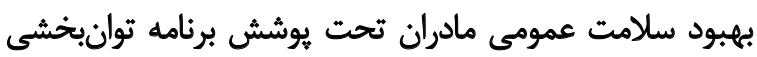
مبتنى بر جامعه شده است سمومي مادران

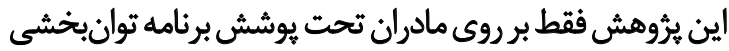

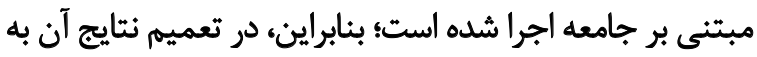

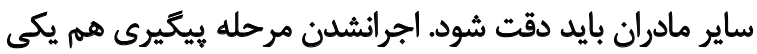

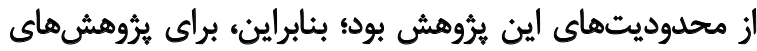

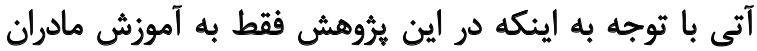

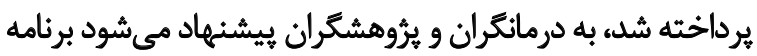

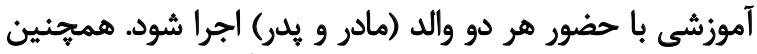

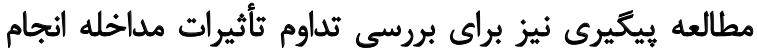

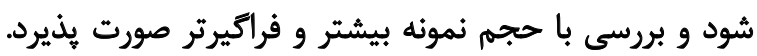

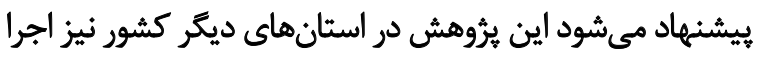

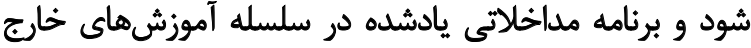

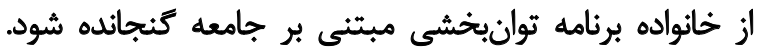

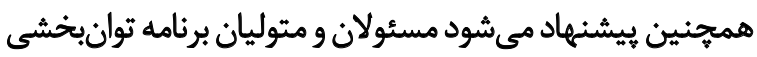

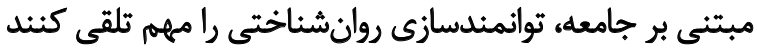

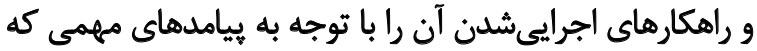
دارد، در داخل كشور مدنظر قرار دهند.

به مسئولان و برنامهريزان سازمان بهزيستى ييشنهاد ميشود

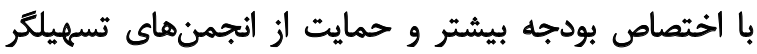

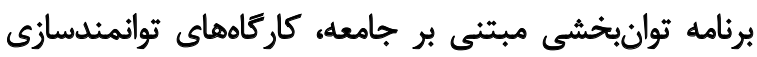
روانشناختى رابراى همه اعضاى خانواده افراد ناتوان بركزار كنيند. توانئ.

\section{مالاحظات اخلاقي \\ ييروى أز اصول الخالاق يثوهش}

شركتكثندكان براى شركت در برؤوش رضايت داشتند.

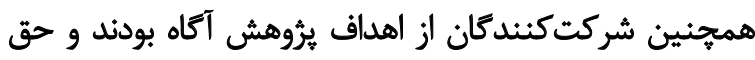

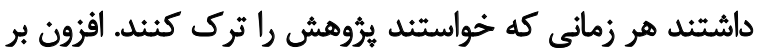

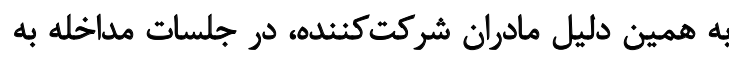

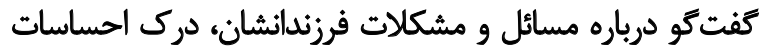

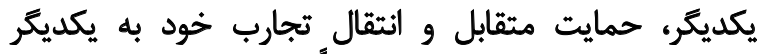

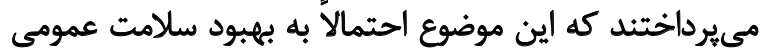

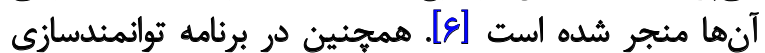

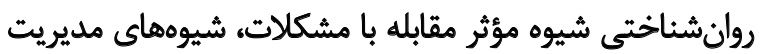

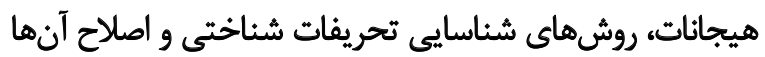

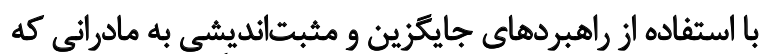

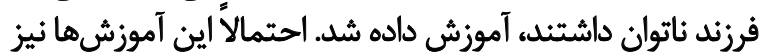

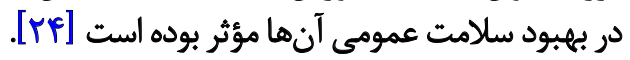

همجنين يافتههاى يُؤوهش نشان داد توانمثندسازى

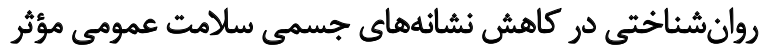

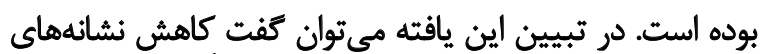

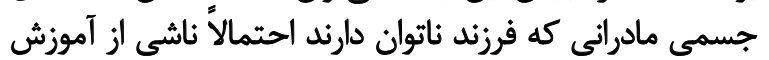

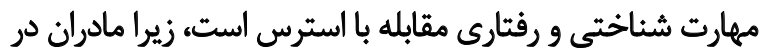

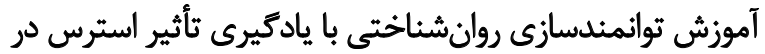

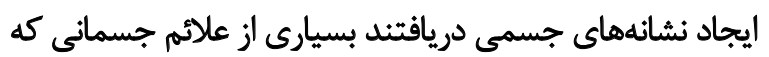

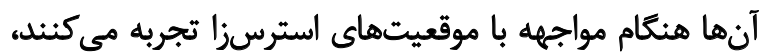

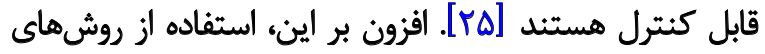

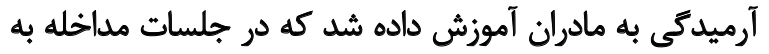

تمرين آن يرداختند [عادران آعوزي

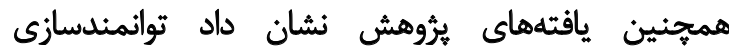

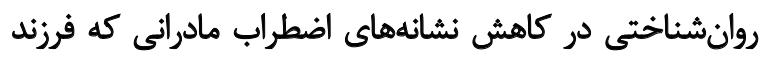

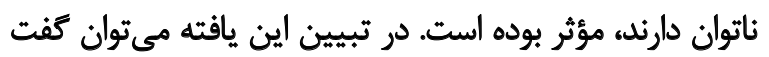

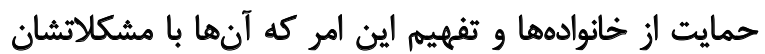

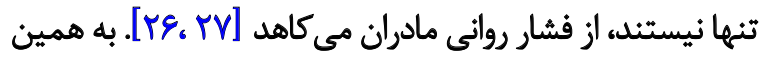

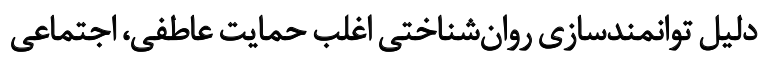

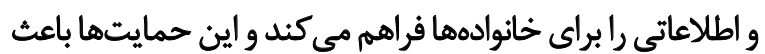

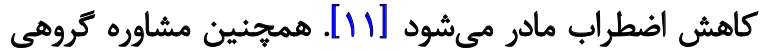

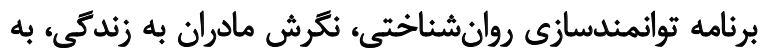

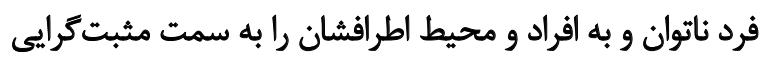

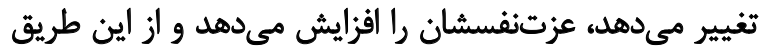
باعث كاهش اضطراب آنان مىشود [YNA]

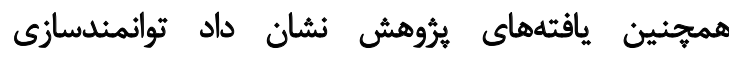
روانشناختى در كاهش نشانههاي اختلال در كاركرد اجتماني

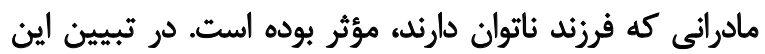

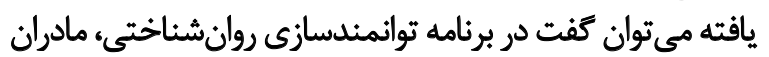

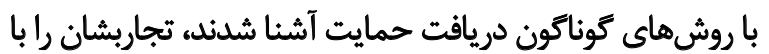

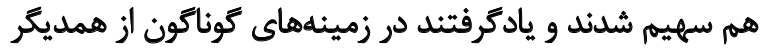

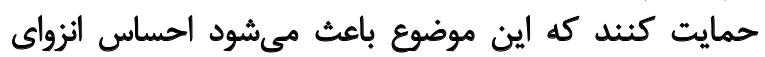

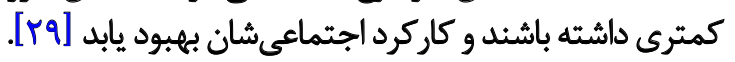
بر اساس يافتهاى اين يُوهش تواتمندسازى روانشناختى بر 
اينء به آنها اطمينان داده شده بود كه اطلاعاتشان هحرمانه

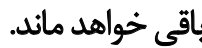

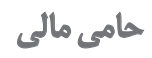

اين يُروهش از جاياننامه كارشناسى ارشد فاطمه فلاحى در

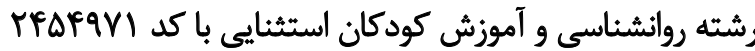

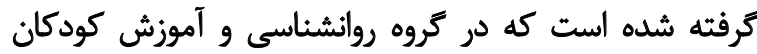
استثنايى دانشكاه شيراز انجام شده است كروه رواتش

\section{مشار كت نويسند مكَان}

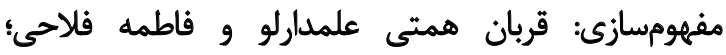

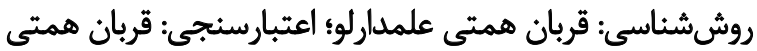

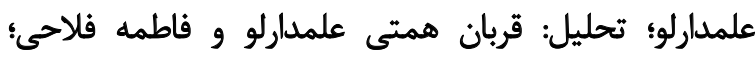

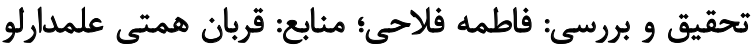

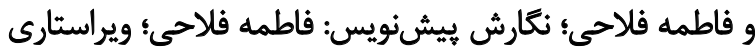

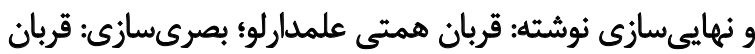

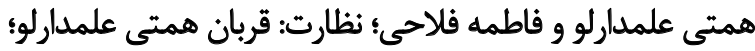

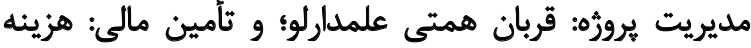

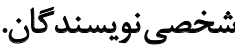

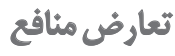

بنا به اظهار نويسندكان، اين مقاله هيجكونه تعارض منافعى ندارد.

$$
\text { تشكر و قدروانئي }
$$

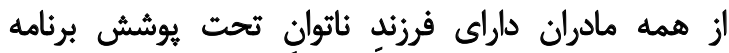

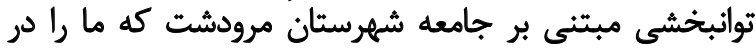

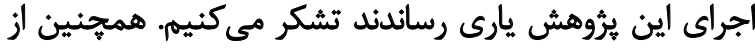

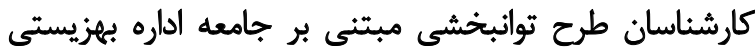

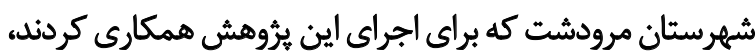
صميمانه سياسكزارى مى مئود. 


\section{References}

[1] Smith TE, Polloway EA, Patton JR, Dowdy CA, Doughty TT. Teaching students with special needs in inclusive settings: Pearson [Gh Hemmati Alamdarloo, AH Khanzadeh, H Alizadeh, Persian trans.]. Tehran: Arasbaran; 2015. [DOI:10.4324/9781315818634]

[2] Soleimani M, Abdi K, Mousavi M. [Comparison of demographic and biological characteristics of parents of children with more than one exceptional child with parents of ordinary children (Persian)]. Archives of Rehabilitation. 2010; 11(5):94-104.

[3] Mauro V, Biggeri M, Grilli L. Does community-based rehabilitation enhance the multidimensional well-being of deprived persons with disabilities? A multilevel impact evaluation. World Development. 2015; 76(c):190-202. [DOI:10.1016/j. worlddev.2015.07.004

[4] Heydari Pour M, Mashhadi A, Asghari Nekah SM. [Relationship between personality characteristics, emotional intelligence and quality of life mental health of people with disabilit (Persian)]. Journal of Rehabilitation. 2013; 14(1):40-9.

[5] Parvinian A M, Kermanshahi S, Sajedi F. [Protective effect of health promotion program on life quality of mothers of children with cerebral palsy (Persian)]. Journal of Rehabilitation. 2012; 13(2):8-17

[6] Keen D, Couzens D, Muspratt S, Rodger S. The effects of a parent-focused intervention for children with a recent diagnosis of autism spectrum disorder on parenting stress and competence. Research in Autism Spectrum Disorders. 2010; 4(2):229-41. [DOI:10.1016/j.rasd.2009.09.009]

[7] Mohammadi Moghadam M, Mobaraki H, Kamali M, Esmaeili A. [Effect of community-based rehabilitation program on quality of life for people of 15-65 years old with severe and profound hearing loss in the city of Sabzevar (Persian)]. Modern Rehabilitation Journal. 2015; 9(2):16-24.

[8] Salamati P, Abolhassani F, Shariati B, Kamali M. [Home based training: Main strategy in community based rehabilitation in Iran (Persian)]. Journal of Rehabilitation. 2006; 7(3):21-5.

[9] Ayoubi Avaz K, Hashemi O, Karami S, Rassafiani M, Hatami R. [Comparison of general health and depression in the people covered with the Community-based Rehabilitation Program (CBR) with the non-covered (Persian)]. Journal of Rehabilitation. 2018; 19(1):54-63. [DOI:10.21859/jrehab.19.1.54]

[10] Raj VS, Thomas M. Effectiveness of training communitybased rehabilitation workers on multiple disabilities: A pilot study. International Journal of Health \& Allied Sciences. 2015; 4(4):259-62. [DOI:10.4103/2278-344X.167654]

[11] Iravani M, Hatami Zade N, Fotouhi A, Hossein Zadeh S. [Comparing effectiveness of new training program of local trainers of community-based rehabilitation program with the current program: A knowledge, attitude and skills study (Persian)]. Journal of Rehabilitation. 2011; 12(3):44-52.

[12] Nazer M, Riyahi N, Mokhtaree MR. [The effect of stress management training with cognitive behavioral style on stress and mental health of parents of children with intellectual disabilities (Persian)]. Journal of Rehabiltation. 2016; 17(1):32-41. [DOI:10.20286/jrehab-170130]
[13] World Health Organization, United Nations Educational, Scientific and Cultural Organization, International Labour Organization \& International Disability Development Consortium. Community-Based Rehabilitation: CBR guidelines. Geneva: World Health Organization; 2010.

[14] Yeh HY, Ma WF, Huang JL, Hsueh KC, Chiang LC. Evaluating the effectiveness of a family empowerment program on family function and pulmonary function of children with asthma: A randomized control trial. International Journal of Nursing Studies. 2016; 60:133-44. [DOI:10.1016/j.ijnurstu.2016.04.013] [PMID]

[15] Salehy Z, Karkhaneh M, Movallali G, Mohammadi MA. Effectiveness of encouragement training in alleviating depression among mothers of children with hearing impairment. Asian Journal of Social Sciences and Management Studies. 2015; 2(2):53-7.

[16] Zahiriniya M. [The need for community-based rehabilitation services for disabled persons (Persian)]. Hormozgan Cultural Research Journal. 2015; 20(3): 217-32.

[17] Ashouri M, Jalilabkenar SS, Hasanzadeh S, Pourmohammadreza Tajrishi M. [Effectiveness of life skill instruction on the mental health of hearing loss students (Persian)]. Journal of Rehabilitation. 2013; 13(4):48-57

[18] Aslani L, Azkhosh M, Movallali G, Younesi SJ, Salehy Z. The ef fectiveness of resiliency training program on the components of quality of life in mothers with hearing-impaired children. Journal of Research \& Method in Education. 2014; 4(3):62-74. [DOI:10.9790/7388-04336266]

[19] Badipoor M, Salimi Bajestani H, Kalantarkousheh SM. [The mothers' psychology empowerment effectiveness on motherchild conflict decreasing in health room of Tehran city (Persian)]. Quarterly Journal of Clinical Psychology. 2012; 6(13):95111

[20] Jafari Mianaei S, Alaei Karahroudi F, Rasouli M. [Study of the impacts of rehabilitation program on mothers with premature hospitalized infants (Persian)]. Journal of Ethics in Education. 2012; 1(1):2-37

[21] Wakimizu R, Yamaguchi K, Fujioka H. Family empowerment and quality of life of parents raising children with developmental disabilities in 78 Japanese families. International Journal of Nursing Sciences. 2017; 4(1):38-45. [DOI:10.1016/j. ijnss.2016.12.004

[22] Mallet P, Hornby G. Counseling in child disability. Skills for working with parents. International Journal for the Advancement of Counselling. 2000; 22(4):331-4. [DOI:10.1023/A:1005625616854]

[23] Doostzadeh $M$. The effectiveness of family timed interventionfocuses on general health and stress symptoms of mothers with hearing impairment [MSc. thesis]. Shiraz: University of Shiraz; 2016.

[24] Farahani M, Basaknejad S, Davoodi I. [The effectiveness of group stress management on aggression,parenting stress and mental health of mothers of children with learning disabilities (Persian)]. Psychological Achievements. 2013; 20(3):217-32. 
[25] Nematollahi M, Tahmasebi S. [The effectiveness of parents' skills training program on reducing children's behavior problems (Persian)]. Quarterly Journal of Family Studies. 2014; 10(38):159-74.

[26] Parand A, Movallali G. [The effect of teaching stress management on the reduction of psychological problems of families with children suffering from hearing-impairment (Persian)]. Journal of Family Research. 2011; 7(1):23-34.

[27] Karimi T, Rangrazian F, Mobasher Amini Z. [The effect of coping strategies with stress on marital satisfaction and stress in parents of children with mantal retardation (Persian)]. Quarterly Journal of Child Mental Health. 2016; 3(3):107-17.

[28] Abdollahi Mehraban N, Shafiabadi A. [Effectiveness of group counseling with a reality therapy approach on increasing self esteem of mothers with Cerebral Palsy (CP) (Persian)]. Research on Behavioral Science. 2014; (3):360-8.

[29] Dennison L, Moss Morris R, Silber E, Galea I, Chalder T. Cognitive and behavioural correlates of different domains of psychological adjustment in early-stage multiple sclerosis. Journal of Psychosomatic Research. 2010; 69(4):353-61. [DOI:10.1016/j. jpsychores.2010.04.009] [PMID]

[30] Khalife Soltani FS, Kamkar M. [The effect of stress management training on the mental health status of dentists in the city of Isfahan, central Iran (Persian)]. Journal of Isfahan Dental School. 2009; 5(3):155-61. 
This Page Intentionally Left Blank 